\title{
TINJAUAN TEOLOGIS TENTANG PENDIDIKAN SEKS DARI PERSPEKTIF PENDIDIKAN KRISTIANI TRANSFORMATIF
}

\author{
Yushiko D. Monding \\ Institut Agama Kristen Negeri Manado \\ Jalan Bougenville, Mandolang, Kabupaten Minahasa, Sulawesi Utara 95661 \\ Email:yushikochyka@gmail.com
}

\begin{abstract}
ABSTRAK. Berdasarkan fenomena yang terjadi dalam masyarakat terkait dengan seks yang dianggap tabu dan tidak patut untuk dibicarakan, serta dampak dosa yang mengakibatkan manusia tidak melihat seks sebagai suatu karunia Allah, artikel ini hendak mendeskripsikan gagasan tinjauan teologis dalam area pendidikan kristiani secara transformatif mengenai pendidikan seks. Metode yang dipakai dalam tulisan ini adalah pendekatan kualitatif secara deskriptif dengan menggunakan studi kepustakaan. Penulis mengkaji berbagai karya literatur yang terkait pembahasan mengenai seks, kemudian merumuskan secara teologis relevansi dan sumbangsih pendidikan kristiani transformatif. Hasil dari studi ini menunjukkan bahwa gereja, keluarga dan sekolah harus memberikan pengajaran atau bimbingan dengan pendekatan teologis edukatif melalui pengajaran Alkitab yang bersifat dinamis.
\end{abstract}

Kata Kunci: pendidikan kristiani transformatif, teologi, pendidikan seks, seks adalah anugerah, pembelajaran Alkitab yang dinamis

\section{THEOLOGICAL ANALYSIS ON SEX EDUCATION FROM THE PERSPECTIVE OF TRANSFORMATIVE CHRISTIAN EDUCATION}

\begin{abstract}
Based on the phenomena that occur in society related to sex, which is considered taboo, and the effect of sin that results in humans not seeing sex as a gift from God, this article is to describe the theological notions in the area of transformative Christian education about sex education. The method used in this paper is a descriptive qualitative approach using a literature study. The author examines various works of literature related to the discussion of sex, then formulates the relevance and contribution of transformative Christian education about sex theologically. The results of this study show that the church, family, and school must provide teaching or guidance with an educational theological approach through dynamic Bible teaching.
\end{abstract}

Keywords: transformative christian education, theology, sex education, sex is a gift, dynamic bible teaching

\section{PENDAHULUAN}

Fenomena mengenai seks menjadi hal yang sudah tidak asing lagi bagi kehidupan masyarakat. Ada beberapa sikap masyarakat terhadap seks, yaitu tidak mau membicarakannya karena dianggap tabu dan perlu untuk dihindari. Namun, ada juga yang terbuka untuk mempercakapkannya sebagai suatu hal yang penting dalam ranah edukasi. Umumnya seks dipahami secara sem- pit sebagai aktivitas persetubuhan atau reproduksi saja. Jikalau hal tersebut menjadi dasar maka aktivitas atau ekspresi seksual dalam bentuk seni, misalnya film, fotografi, tarian dan lain sebagainya, maka masyarakat yang berpandangan kultur tabu tadi secara subyektif akan memberikan istilah pornografi yang bermakna negatif. Istilah subyektif dapat dikatakan bersifat relatif karena ada berbagai macam penilaian 
mengenai pantas atau tidaknya ekspresi seksual yang menyangkut konsep aurat manusia (Hidir, 2017). Ada juga sebagian masyarakat yang mau terbuka untuk berbicara mengenai seks. Saat sekarang ini juga sudah mulai dikembangkan berbagai macam acara seminar atau talk show, yang selalu banyak disaksikan oleh masyarakat dari berbagai golongan. Hal ini dikarenakan ada semacam kesadaran pembicaraan mengenai seks sebagai hal yang riil karena seksualitas merupakan atribut manusia. Bahkan organisasi pendidikan, ilmu pengetahuan dan kebudayaan PBB (UNESCO) memberikan saran bahwa setiap negara seharusnya mengajarkan pendidikan seksual secara komprehensif dan dimulai sejak dini agar dapat memahami fakta-fakta mendasar tentang tubuh, keluarga, hubungan sosial dan lain sebagainya, termasuk di Indonesia (CNN Indonesia, 2019).

Di saat sekarang ini kehidupan media sosial semakin berkembang, siapa pun khususnya generasi muda bisa dengan bebas mengakses pornografi untuk memenuhi kebutuhan pengetahuan atau rasa penasaran yang tinggi terhadap seksualitasnya. Menjadi suatu masalah jikalau tidak ada pendidikan seks. Informasi di internet yang tidak disaring oleh mereka bisa berdampak negatif. Bukannya mendapatkan informasi edukasi yang akurat mengenai seks dan reproduksi, mereka justru jatuh pada hal-hal negatif, misalnya melakukan seks di luar nikah, hidup bersama tanpa adanya ikatan pernikahan dan lain sebagainya (Kirnandita, 2018).

Menyikapi hal-hal di atas, maka penting untuk meninjau mengenai seks secara khusus dari perspektif teologis biblis yang kemudian diimplementasikan dalam ranah Pendidikan Kristen. Hal ini merupakan hal yang penting dikarenakan setiap orang percaya perlu memiliki pengertian yang baik dan benar mengenai seks dalam kerangka Alkitab, sehingga kita bisa menghargai keagungan dan kesucian seks itu sendiri. Artikel ini mencoba mendeskripsikan serta mengkaji walaupun tidak secara mendetail namun dapat memberikan sumbangsih secara luas dalam kerangka teologis biblis edukatif tentang seks dari perspektif pendidikan kristiani transformatif.

\section{METODE}

Penelitian ini menggunakan pendekatan kualitatif, di mana penelitian memecahkan masalah menggunakan data empiris (Masyhuri \& Zainudin, 2009, p. 13). Langkah-langkah yang dilakukan dalam pendekatan ini harus serasi dan saling mendukung satu dengan yang lainnya agar penelitian atau penulisan yang dilakukan mempunyai bobot yang cukup memadai dan memberikan hasil atau jawaban yang tidak meragukan. Langkah yang selanjutnya dilakukan adalah mencari teori, gagasan atau konsep yang dapat dijadikan dasar teoritis bagi penulisan yang dilakukan. Landasan ini sangat diperlukan agar peneliti memiliki satu acuan yang kokoh dan bukan sekadar hanya mencoba mendapatkan informasi dari hal yang diteliti

Metode penelitian kualitatif dalam artikel ini bersifat deskriptif dengan menggunakan pendekatan studi kepustakaan. Metode kepustakaan sendiri adalah kegiatan penelitian ilmiah yang menelaah secara kritis dan mendalam bahan-bahan pustaka yang relevan. Penelaahan ini dilakukan dengan cara mengumpulkan data-data atau berbagai macam informasi dari sumbersumber pustaka yang kemudian disajikan dengan bentuk baru untuk keperluan baik akademis maupun praktis (Kaelan, 2005, hlm. 254). Selain itu, pendekatan studi kepustakaan yang digunakan adalah model kualitatif faktual, yaitu analisis tekstual bukubuku teologis yang diinterpretasikan untuk mendapatkan makna dari teks sosial atau fenomena kultural (Subagyo, 2004, p.118).

Pada umumnya analisis data dalam penelitian kualitatif kepustakaan, difokuskan selama proses mengkaji secara literatur untuk proses pengumpulan dan pengolahan data. Adapun dalam penulisan ini, penulis 
menggunakan dua strategi analisis data yang digunakan, yaitu model analisis deskriptif kualitatif dan juga model strategi analisis verifikatif. Pengolahan dan analisis terhadap data-data terkait fenomena operasi transeksual menggunakan metode deskriptif eksploratif. Metode kualitatif deskriptif dengan pendekatan kepustakaan yang eksploratif untuk meninjau, mengkaji serta merumuskan seperti apa konsep pendekatan teologis mengenai seks dalam perspektif pendidikan kristiani transformatif. Hasil analisis terhadap seks secara teologis alkitabiah kemudian dirumuskan melalui kerangka Pendidikan Kristen transformatif.

\section{HASIL DAN PEMBAHASAN}

\section{Pendidikan Kristen}

Menurut Homrighausen Pendidikan Kristen berpangkal pada persekutuan umat Tuhan itu sendiri. Pendidikan Kristen dimulai pada saat dipanggilnya Abraham yang kemudian menjadi leluhur bangsa Israel, dan Allah sendiri merupakan pengajar utama serta umat pilihan-Nya menjadi peserta didik (Homrighausen \& Enklaar, 2009, p. 12). Kristanto berpendapat bahwa Pendidikan Kristen merupakan suatu proses belajar-mengajar yang berlandaskan pada Firman Tuhan, dengan Kristus sebagai pusat pembelajarannya serta Roh Kudus menjadi pengarah dalam proses belajar tersebut. Dalam proses pembelajaran ini, dapat dilihat lagi bahwa Allah Trinitas sangat berperan bagi naradidik untuk mengarahkan mereka bertumbuh melalui pengajaran sesuai dengan rencana dan kehendak Allah di dalam Yesus Kristus dalam setiap aspek kehidupan (Kristanto, 2006, p. 4). Harianto menyatakan juga bahwa Pendidikan Kristen didasarkan pada kebenaran Firman Tuhan. Alkitab mengungkapkan bahwa manusia adalah ciptaan Allah yang harus memuliakan Allah, sehingga pendidikan tidak hanya berbicara tentang ilmu pengetahuan, tetapi tuntutan moralitas Allah (GP, 2012, p. 52). Boehlke juga menambahkan bahwa
Pendidikan Kristen adalah usaha gereja dengan sengaja menolong orang dari segala umur yang dipercayakan kepada pemeliharaan-Nya untuk menjawab penyertaan Allah dalam Yesus Kristus, Alkitab dan kehidupan gereja, supaya mereka dipimpinan Roh Kudus dan dapat diperlengkapi untuk melayani di tengah lembaga gereja, masyarakat dan dunia (Boehlke, 2009, p.546). Dari beberapa pernyataan di atas dapat dikatakan bahwa Pendidikan Kristen berfokus untuk mengajarkan mengenai pokok-pokok kebenaran iman Kristen, pengetahuan secara sistematis dan alkitabiah untuk menjaga kelakuan rohani naradidik. Dengan mengetahui dan memahami landasan Pendidikan Kristen yang dapat menjadi suatu kerangka pembelajaran, serta pengajaran nilai-nilai Kristen untuk dapat diterapkan dalam kehidupan sosial atau lingkungan sekitar yang di dalamnya terdapat berbagai macam isu termasuk kehidupan seksualitas bagi keluarga atau jemaat.

\section{Seks Menurut Alkitab}

Dari Perspektif Alkitab, seks mengandung banyak gagasan. Seks bersifat suci karena sesuai dengan rencana ketetapan Allah yang ada dalam kekekalan. Dalam perspektif ciptaan Allah, seks adalah kasih karunia, yang merupakan unsur vital untuk setiap makhluk hidup (Purnomo, 2013). Manusia diciptakan menurut gambar dan rupa Allah, kemudian semua ciptaan tersebut disebut "baik", namun karena Adam pada awalnya diciptakan sendiri, dan tidak memiliki pasangan, disebut "tidak baik" oleh Allah. Oleh karena itu Allah menciptakan Hawa sebagai penolong Adam untuk menemaninya. Jadi, hubungan secara heteroseksual di antara mereka sangat indah karena termasuk dalam pola ciptaan Allah. Manusia membutuhkan pendamping dalam aspek fisik, jiwa serta kerohanian. Allah menciptakan jenis kelamin yang berbeda harus dilihat dari perspektif anugerah Allah yang Dia berikan kepada manusia sebagai makhluk ciptaan-Nya 
untuk menjalani kehidupan mereka di dunia. Maksud Tuhan mengaruniakan "Penolong yang sejodoh" adalah agar kedua pasangan menjalin "partnership, " yakni suatu kesatuan yang terdiri dari pria dan wanita, sebagai teman hidup yang saling tolong menolong, saling mengasihi dan saling melengkapi. Hal ini disebabkan adanya alasan bahwa tidaklah baik kalau manusia itu seorang diri saja (Kej. 2:18-25). Jadi hakikat seksualitas manusia tidak bisa dipisahkan dari maksud Tuhan agar terjadi persatuan hati dan persatuan kasih antara kedua jodoh itu (Herlianto, 2013).

Selain itu, penyebutan jenis kelamin yang berbeda untuk manusia di sini merupakan sesuatu yang penting untuk diperhatikan, karena Alkitab tidak mencatat perbedaan jenis kelamin binatang di Kejadian 1, walaupun mereka tentu saja berjenis kelamin yang berbeda (Handoko, 2016). Manusia dalam pandangan Allah itu baik. Allah menetapkan suatu tujuan ketika la menjadikan seks bagi manusia. Seks merupakan ciptaan Allah yang kudus serta mulia, seperti yang diungkapkan dalam 1 Timotius 4:4-5. Seks merupakan rancangan karya Allah yang dicipta serta dikuduskan oleh-Nya. Seks bukan merupakan suatu hal yang jahat, kotor melainkan seks adalah hal yang baik. Seperti dijelaskan dalam Kitab Kejadian, "Beranak cuculah dan bertambah banyak agar memenuhi bumi dan berkuasa atasnya" (Kej. 1:28). Maka seks adalah bagian rencana Allah untuk memenuhi maksud-Nya bagi dunia ini (Tu'u, 1988, p. 11). Perlu menjadi perhatian bersama bahwa oleh karena kejatuhan Adam yang berakibat pada dosa manusia, tubuh pun ikut rusak dan dikutuk (Kej. 3:16-19). Oleh karena manusia telah berdosa maka murka Allah nyata dalam kehidupan manusia $(\mathrm{Rm}$. 1:18-19). Setiap pekerjaan, aktivitas manusia menjadi sulit oleh karena kutukan dari Allah. Tubuh manusia mengalami proses kerusakan yang pada akhirnya mendatangkan kematian. Pada waktu penciptaan terhadap manusia, mereka adalah sem- purna tetapi karena dosa menjadi menderita. Segala macam penyakit juga akibat dari kutukan Tuhan karena manusia yang tidak taat akan perintah-Nya. George Scipione menjelaskan mengenai kegagalan genetik tubuh yang mengakibatkan masalah pada kehidupan seksual manusia (Scipione, 2010). Menurut Susabda yang berpendapat bahwa Alkitab menjelaskan tentang adanya "ketidaknormalan" mengenai seks dan juga perilaku seksualitas yang telah terjadi oleh karena akibat dosa, yaitu rusaknya hubungan dengan Allah. Sebelum kejatuhan dalam Kej 2:25, manusia telanjang tapi tidak merasa malu. Hubungan antara laki-laki dan perempuan adalah hubungan sosial seutuhutuhnya. Seks adalah perlengkapan dan alat sosial, yaitu sesuatu yang menyatukan manusia seutuhnya. Sesudah kejatuhan dalam Kej 3:7, dosa membuat manusia tidak dapat membina hubungan sosial seutuhnya dengan sesamanya. Seks semata-mata menjadi alat pelampiasan nafsu. Rusaknya hubungan dengan Allah menyebabkan rusaknya juga hubungan dengan sesamanya, yakni antara laki-laki dan wanita. Manusia tidak dapat lagi melihat kesatuan antara kebutuhan seksual dengan kebutuhan sosial (Susabda, 2015, p. 118). Dapat dikatakan bahwa dosa yang membawa dampak buruk bagi kehidupan manusia termasuk seks. Seks yang pada awalnya diciptakan untuk maksud dan tujuan untuk kemuliaan Allah sekarang menjadi buruk serta disalahgunakan sebagai pemuas hawa nafsu belaka.

\section{Seks Berdasarkan Perspektif Bapa-bapa Gereja}

Tertulianus adalah seorang penulis Kristen yang berasal dari Kartago dan juga seorang apologet Kristen awal dalam melawan ajaran sesat. Pandangan-pandangan teologis Tertulianus mengenai seks atau seksualitas bisa dikatakan ekstrim. Suleemaan mengutip tulisannya, De Cultu Feminarum, dengan mengatakan, 
Tidak tahukah engkau adalah Hawa? Penghakiman Allah terhadap kehidupan seks ini hidup terus sampai sekarang. Karena itu, maka kesalahan itu pun hidup terus. Engkau adalah pintu gerbang si Iblis. Engkaulah yang membuka meterai kutukan pohon itu, dan engkaulah yang pertama kali memalingkan diri dari hukum ilahi. Engkaulah yang membujuknya (Adam), yang iblis tidak mampu merusakkannya. Engkau dengan mudah menghancurkan gambar Allah, Adam. Karena apa yang layak engkau terima, yakni maut, bahkan Anak Allah harus mati." (Suleeman, 2013, p.3).

Lebih lanjut lagi dikatakan,

Tertulianus menerima pernikahan namun menolak poligami. la berkata; "Kami memang tidak melarang kesatuan diantara laki-laki dan juga perempuan, yang samasama diberkati Allah sebagai tempat persemaian ras manusia, serta dirancang untuk memenuhi bumi dan melengkapi dunia dan dengan demikian diizinkan, tapi hanya dengan satu orang saja. Karena Adam adalah satu suami dari Hawa, dan Hawa adalah istrinya yang hanya satu saja, satu perempuan, satu tulang rusuk (Suleeman, 2013, p.4).

Agustinus, seorang Bapa Gereja terkenal. Pada masa mudanya ia hidup berganti-ganti pasangan dan kemudian hidup dengan seorang perempuan di luar ikatan pernikahan. Pengalaman seksual Agustinus yang serba bebas pada masa mudanya sebelum ia menjadi Kristen sangat memengaruhi pemikiran etis mengenai seks. Menurutnya, kesatuan laki-laki dan perempuan dengan tujuan prokreasi adalah kebaikan alami dari perkawinan. Akan tetapi, Agustinus menyalahgunakan kebaikan ini yang menggunakannya seperti binatang, sehingga tujuannya adalah pada pemuasan hawa nafsu, dan bukan pada keinginan untuk mendapatkan keturunan (Suleeman, 2013 p. 5). Agustinus menambahkan bahwa nafsu seksual adalah sesuatu yang buruk, tetapi menurutnya manusia juga masih dapat memanfaatkan sisi-sisi baik dari keburukan tersebut. la percaya bahwa apabila seks digunakan untuk menghasilkan keturunan dalam lingkup pernikahan, maka seks itu baik sedangkan kalau hanya untuk kesenangan belaka, maka seks itu menjadi tidak baik (Suleeman, 2013, p.5).

\section{Pandangan Para Reformator}

Martin Luther memandang bahwa seks merupakan hal yang kudus, suci serta erat kaitannya dengan kehidupan manusia khususnya kehidupan pernikahan. Luther menjelaskan juga bahwa perempuan bukan budak dari suami. Perempuan punya hak yang penuh terhadap kehidupan mereka termasuk kehidupan seks (Marius, 2009, p. 6). Tentang hubungan seksual, Luther berpendapat bahwa pasangan yang sedang berhubungan seksual tidak boleh melepaskan seluruh pakaiannya karena mereka tidak boleh saling merangsang secara berlebihan, dan mereka tidak boleh menjadikan tempat tidur mereka semacam "a manure heap and a sow bath" dengan menggunakan berbagai teknik dan posisi (Karant-Nunn \& Wiesner-Hanks, 2003, p.12).

John Calvin merumuskan secara sistematis dengan kerangka hukum pemerintahan gereja yang diterapkan dalam aspek kehidupan sosial untuk mengatur berbagai macam masalah jemaat termasuk kaitannya dengan seksualitas. la mendorong mereka yang sudah dewasa dan siap menikah untuk menikah. Bukan hanya itu, ia telah memperlengkapi dengan pedoman untuk berpacaran dan bertunangan. Dalam hal waktu untuk pertunangan, para pasangan tidak diperkenankan hidup sebagai suami istri, sampai pernikahan mereka disahkan di gereja. Kalau kedapatan melakukan hubungan seksual sebelum pernikahan diresmikan, mereka dianggap berzina dan akan dipenjarakan selama tiga hari dan hanya diberi makan roti dan minum air (Thianto, 2001, p. 197). Dalam kaitan 
dengan pernikahan, ia mengangkat hak dan kewajiban yang seharusnya ada pada seorang istri, dan mengungkapkan tentang perceraian-perceraian dengan alasan yang salah. la juga menyusun dasar peraturan dan prosedur bagi pembatalan pernikahan (Rusli, 2009, p. 74).

\section{Pendidikan Kristiani Transformatif}

Pendidikan kristiani transformatif merupakan sebuah percakapan kehidupan dengan menggunakan sumber iman dan tradisi kultural dalam menghadirkan masa yang lebih baik dan berpengharapan. Pendidikan kristiani transformatif juga mengarahkan perhatian pada misi gereja di dunia, peran komunitas iman, pemahaman dan pengajaran.

Transformasi menjadi tujuan dan proses pendidikan hingga Kerajaan Allah yang penuh keadilan dan kasih diwujudkan (Seymour, 2016, p. 15). Gereja merupakan concern utama terhadap lingkungan pembelajaran yang harus bersifat transformatif agar dapat terjadinya pertumbuhan iman serta mengubah paradigma baik secara personal maupun komunal ke arah moralitas Allah. Pendidikan dalam lingkungan gereja adalah panggilan pelayanan yang harus dilakukan untuk mengarahkan, membimbing dan mengarahkan sesuai dengan kehendak Allah (O'Gorman, 1997, p. 41). Pendidikan Kristiani Transformatif haruslah terampil mengenali dalam upaya untuk dapat menciptakan keadilan, perdamaian, kasih dan harapan di tengah-tengah dunia, melalui anugerah ilahi dan solidaritas serta persekutuan. Dengan demikian, setiap orang percaya harus masuk ke dalam solidaritas bersama dengan komunitas yang menderita dan ditolak (Toton, 2006, p. 42).

Dengan mengamati keberagaman dalam pendekatan terhadap Pendidikan Kristen, maka diupayakan suatu kesatuan perspektif dengan memandangnya sebagai suatu tugas Pendidikan Kristen yang sama dengan komponen yang lainnya yaitu: (1) masuk ke dalam bidang-bidang kehidupan di dunia adalah tugas utama Pendidikan Kristiani; (2) jemaat adalah perhatian dasar utama Pendidikan Kristen; (3) refleksi secara teologis biblis merupakan suatu pendekatan yang baik; serta (4) pembelajaran agama harus dilakukan di dalam hospitalitas, keadilan, dan ruang yang terbuka untuk percakapan dan pengungkapan kebenaran (Harjanto, 2019, p. 51). Dengan penjelasan di atas, maka pendidikan kristiani transformatif dapat memberikan suatu pembelajaran iman dengan kerangka solidaritas, kasih dan pengharapan kepada komunitas iman, khususnya masalah-masalah seputar seksualitas yang juga menjadi suatu pergumulan yang dihadapi setiap orang percaya.

\section{Seks dalam Perspektif Pendidikan Kristiani Transformatif}

Seperti yang telah dijelaskan sebelumnya bahwa kasih, solidaritas dan pembelajaran merupakan bagian-bagian yang harus ada dalam pendidikan kristiani transformatif guna untuk memberikan suatu pengarahan, bimbingan atau hospitalitas bagi kehidupan jemaat terkait tema mengenai seks yang banyak dianggap tabu bagi sebagian orang, bahkan terhadap komunitas orang percaya itu sendiri.

Pendidikan seks merupakan salah satu cara untuk mengurangi atau mencegah penyalahgunaan seks. Perlu diperhatikan bahwa pendidikan seks bukanlah penerangan tentang seks semata-mata. Informasi secara edukatif tentang seks tidak diberikan secara "telanjang", melainkan diberikan secara "kontekstual", yaitu dalam kaitannya dengan norma-norma yang berlaku dalam masyarakat (Sarwono, 2016, p. 235).

Pendidikan seks merupakan pengetahuan tentang hal-hal yang berkaitan dengan jenis kelamin dan juga fungsi kelamin sebagai alat reproduksi. Tahapannya dapat dilihat bahwa adanya suatu perkembangan kelamin pada laki-laki, perempuan, fase menstruasi, mimpi basah dan pada tahap selanjutnya tahap birahi karena adanya 
perubahan hormon pada laki-laki dan perempuan. Kemudian masuk pada tahap perkawinan, kehamilan dan lain sebagainya (Marbun, 2019, p. 334). Dari beberapa pernyataan di atas dapat dikatakan bahwa pendidikan seks merupakan suatu upaya memberikan pengetahuan mengenai organ reproduksi dengan menanamkan moral, etika, serta komitmen agama agar tidak terjadi penyalahgunaan organ reproduksi tersebut.

Dalam konteks teologis, hal yang perlu diperhatikan mengenai pendidikan seks bukan hanya pendidikan yang sifatnya mengajarkan atau memberikan pengetahuan tentang seks saja tetapi meliputi sifat moral, penekanan pada perilaku seksual yang terdistorsi karena dosa (Soesilo, 2013, p. 15). Selanjutnya, pendidikan seks juga mencakup dua hal. Pertama, Tuhan menciptakan manusia sebagai laki-laki dan perempuan (Kej.1:26), sehingga manusia bertumbuh sesuai dengan kodratnya. Kedua, karena manusia telah diciptakan sesuai dengan gambar dan rupa-Nya, maka manusia itu suci, termasuk dalam hal seksual, manusia harus menjaga kesucian serta kekudusannya (Borrong, 2006, p. 57).

Lebih lanjut, perlu ditekankan bahwa Pendidikan seks baik dalam ranah formal maupun informal, memang perlu untuk diajarkan kepada generasi muda (pemuda dan remaja) secara berkelanjutan dan juga bertahap. Seks tidak hanya mencakup yang berkaitan dengan moralitas meskipun itu adalah bagian penting yang harus dibicarakan. Pendidikan seks dalam lingkup kristiani perlu menekankan aspek institusi pernikahan yang diakui masyarakat juga gereja. Hal ini disebabkan karena seks tidak semata-mata masalah kebutuhan fisik atau saling mencintai saja, karena yang paling penting adalah bahwa seks diatur atau berada di bawah ketetapan Tuhan sendiri, karena jikalau tidak dilaksanakan sesuai kehendak-Nya hal tersebut menjadi dosa (Gunadi, 2018).

\section{Prinsip-prinsip Teologis Pendidikan Kristiani Transformatif Mengenai Seks}

Pendidikan kristiani transformatif merupakan tindakan pengajaran yang diharapkan mampu untuk memberikan pengaruh yang baik mengenai seks bagi setiap orang percaya. Dalam hal ini keluarga, gereja bahkan sekolah perlu untuk memahami pengajaran secara edukatif dan pembimbingan secara rohani yang alkitabiah. Ada beberapa prinsip yang bisa dilaksanakan terkait pendidikan seks yang berlandaskan nilai-nilai teologis biblis:

\section{Pendidikan Kristiani Transformatif dalam Keluarga}

Pendidikan kristiani tentang seks idealnya dimulai dari keluarga. Namun seperti yang dikatakan pada bagian awal, bahwa sebagian orang merasa tabu untuk membicarakan hal-hal yang berkaitan dengan seks terhadap seluruh anggota keluarga khususnya anak-anak. Oleh karena itu perlu untuk ditekankannya informasi yang baik melalui Pendidikan Kristen tentang bergereja secara teologis edukatif kepada keluarga sebagai pembinaan untuk mengenal diri sendiri selaku ciptaan Allah menurut citra-Nya. Orang tua adalah pihak yang bertanggung jawab dalam memenuhi kebutuhan rohani anggota keluarganya. Memenuhi kebutuhan rohani seorang anak berarti sudah melindungi anak dari berbagai macam pengaruh yang ada. Orang tua harus mampu memberikan nilai-nilai yang kekal bagi anak-anaknya yakni dengan memperkenalkan Kristus Yesus sebagai jalan keselamatan, kemudian bersekutu bersama untuk berdoa, menghafal dan memahami ayat Firman Tuhan dan beribadah singkat.

\section{Pendidikan Kristiani Transformatif oleh Gereja.}

Gereja mempunyai tanggung jawab dalam pemenuhan kerohanian jemaat, hubungan yang intim dengan Tuhan serta relasi yang berdasarkan kasih antar sesama 
dapat melahirkan perilaku yang menghormati dan taat kepada perintah Tuhan. Gereja melalui proses pembelajaran, serta pengajaran dapat memberikan suatu pemahaman yang alkitabiah tentang seks, serta merangkul dan mendorong untuk lebih dekat kepada Tuhan (Purnama \& Tarigan, 2011, p.125). Gereja memberikan pendidikan terhadap umat Tuhan untuk membimbing serta menolong mereka agar dapat hidup bertanggung jawab dalam menjaga kesucian hidup serta mempunyai paradigma baru yang sudah ditransformasi melalui pimpinan dan penyertaan Roh Kudus (Gunawan, 2016, p. 10). Selanjutnya, Gereja, melalui para pemimpin atau hamba-hamba Tuhan melakukan percakapan atau dialog untuk merefleksikan pengalaman hidup terkait dengan seks dalam terang Alkitab. Tugas pemimpin adalah untuk memimpin, mendengarkan, dan masuk ke dalam pembicaraan khususnya mengenai seks. Bentuk pertemuan pembelajaran ini dimulai dengan teks Alkitab lalu dilanjutkan dalam pengalaman rekan-rekan komunitas iman, membandingkan pengalaman-pengalaman tersebut dengan teks-teks Alkitab. Suasananya dipenuhi dengan ikatan emosional dan perasaan mendalam yang berkembang dalam kurun waktu tertentu (Seymour, 2016, p. 54).

\section{Pendidikan Kristiani Transformatif di Sekolah.}

Selain orang tua, para guru juga dituntut memiliki kepekaan, keterampilan dan pemahaman benar sesuai dengan kebenaran Firman Tuhan agar mampu memberi informasi dalam porsi tertentu, yang membuat peserta didik tidak menjadi bingung dalam pola pembelajaran mereka. Guru-guru dan juga orang tua selayaknya bersinergi untuk memberikan pendidikan seks yang baik dan benar. Mereka memiliki tanggung jawab terhadap hal tersebut. Sejak dini, pendidikan seks harus diketahui dan dipahami oleh peserta didik atau anakanak supaya mereka mengerti dan memahami tentang seks secara utuh.

Pendidikan seks dan peran gender merupakan bagian penting dari pendidikan dasar, moral dan ibadah. Apabila pendidikan seks dan peran gender diabaikan maka seks menjadi tabu. Seperti yang dikatakan oleh Staton,

Pembentukan akhir dari identitas anak
sebagai anak laki-laki atau perempuan
pada umumnya terjadi sebelum usia lima
tahun. Antara usia tiga dan lima tahun,
anak-anak mengalami rasa ingin tahu
yang sangat besar dan melakukan
identifikasi yang mendalam sehubungan
dengan masalah jenis kelamin" (Stanton \&
Jones, 2004, p.171).

Oleh karena itu, dibutuhkan usaha untuk menjawab rasa ingin tahu dengan baik kepada anak tentang seks dengan bersikap terbuka dan menjalin komunikasi yang efektif dengan mereka yang tentunya sesuai dengan kapasitas usia dan intelektualnya. Di sini para guru harus memahami pentingnya kurikulum pendidikan seks dan peran gender pada anak.

\section{KESIMPULAN}

Berdasarkan pembahasan yang telah dikemukakan dalam tulisan ini, maka dapat disimpulkan bahwa seks pada dasarnya adalah baik, suci serta sesuai dengan rencana ciptaan Allah yang bersifat kekal. Seks dalam konteks teologis adalah suatu kasih karunia. Namun dosa, yakni ketidaktaatan manusia, juga memengaruhi perilaku seksualitas manusia. Seks menjadi indah apabila diintegralkan dalam lingkup pernikahan seperti yang ditekankan oleh bapabapa gereja dan juga para reformator. Selain itu, pendidikan kristiani transformatif dalam lingkup keluarga, gereja dan sekolah dapat memberikan pertolongan dan bimbingan kepada umat-Nya secara teologis biblis mengenai seks, khususnya bagi generasi muda. Melalui pendidikan transformatif mengenai seks yang diajarkan berdasarkan nilai-nilai kristiani, sudah saatnya setiap 
umat Tuhan tidak lagi menganggap tabu, atau kontra terhadap istilah seks. Karena melalui pengajaran atau bimbingan yang benar dalam terang Firman Tuhan, maka

\section{DAFTAR RUJUKAN}

Boehlke, R. (2009). Sejarah Perkembangan dan Praktik Pendidikan Agama Kristen 1. Jakarta: BPK Gunung Mulia.

Borrong, R. P. (2006). Etika Seksual Kontemporer. Bandung: Ink Media.

CNN Indonesia. (2019). UNESCO: Pendidikan Seks Harus Diterapkan Secara Kompherensif, Retrieved from https://cnn.indonesia.com/gayahidup/20190614052418-255403174/unesca-pendidikan-seksharus-diterapkan-secara-komprehensif

Gunadi, P. (2018). Pendidikan Seks dalam Keluarga. Retrieved from http://remaja.sabda.org/pendidikanseks-dalam-keluarga

Gunawan, L. (2016). Kesetaraan dan Perbedaan Laki-laki dan Perempuan: Kritik Terhadap Gerakan Feminisme. Jurnal Societas Dei, 3(2), 288-313

GP, Harianto. (2012). Pendidikan Agama Kristen dalam Alkitab dan Dunia Pendidikan Masa Kini. Yogyakarta: ANDI

Handoko, T. Y. (2016). Perspektif Alkitab tentang Seks. Retrieved from https://star-

exodus.org/publikasi/artikel/2016/02/2

016/perspektif-alkitab-tentang-seks/

Harjanto, S. (2019). Visi Pendidikan Berdasarkan Konsep Panggilan: Upaya Menemukan Arah yang Menyatukan Pendidikan Kristen di Berbagai Konteks. Indonesian Journal of Theology, 7(1), 46-71.

Herlianto. (2013) Seksualitas Menurut Alkitab. Retrieved from http://alkitab.sabda.org/resource.php?t opic $=75 \&$ res $=$ jpz

Hidir, A. (2017) Ambiguitas Pendidikan Seks di Indonesia. Retrieved from https://www.kompasiana.com/achmad seks tidak lagi dianggap negatif melainkan bagian dari kasih karunia dari Allah terhadap ciptaan-Nya.

hidir/59004d98f07a614d20a71cf5/amb iguisitas-pendidikan-seks-di-indonesia

Homrighausen, E. G. \& Enklaar, I. H. (2009). Pendidikan Agama Kristen. Jakarta: BPK Gunung Mulia.

Kaelan, M. S. (2005). Metode Penelitian Kualitatif Bidang Filsafat. Paradigma: Yogyakarta.

Karant-Nunn, S. C. \& Wiesner-Hanks, M. E. (2003). Luther on Women. Cambridge: University Press.

Kirnandita, P. (2018) Pengetahuan Seks adalah Tabu: Bikin Malu Sekaligus Penasaran. Retrieved from https://tirto.id/pengetahuan-seksadalah-tabu-bikin-malu-sekaliguspenasaran-cEHw

Kristanto, P. L. (2006). Prinsip dan Praktik PAK Penuntun bagi Mahasiswa Teologi dan PAK, Pelayan Gereja, Guru Agama dan Keluarga Kristen. Yogyakarta: ANDI

Marbun, S. M. \& Stevanus, K. (2019). Pendidikan Seks pada Remaja. FIDEI: Jurnal Teologi Sistematika dan Praktika, 2(2), 325-343

Marius, R. (2009). Martin Luther: The Christian between God and Death. Cambridge, MA: Harvard University Press

Masyhuri \& Zainudin, M. (2009). Metodologi Penelitian: Pendekatan Praktis dan Aplikatif. Bandung: Refika Aditama.

O'Gorman, R. T. (1997). The Faith Community. In S. L. Seymour (Ed.), Mapping Christian Education: Approaches to Congregational Learning (pp. 41-57). USA: Abingdon Press.

Purnama, I. W. \& Tarigan, I. W. (2011). Tinjauan Etika Kristen Terhadap Operasi Transeksual. Jurnal Jaffray, 9(1), 109-130 
Purnomo, D. P. (2013). Menjawab Pertanyaan-pertanyaan Kontemporer. Retrieved from http://sabda.net/modul/id_PURNOMO KONTEMPORER

Rusli, M. (2009). Konsistensi Antara Pengajaran Calvin akan Pernikahan Kristen dan Hidup Pernikahannya. Veritas: Jurnal Teologi dan Pelayanan, 10(1), 73-95

Sarwono, S. W. (2016). Psikologi Remaja. Jakarta: Rajawali Pers

Scipione, G. C. (2010). The Biblical View of The Body. Retrieved from http://www.ipdx.org.html

Seymour, J. L. (2016). Memetakan Pendidikan Kristiani: Pendekatanpendekatan Menuju Pembelajaran Jemaat. Jakarta: BPK Gunung Mulia

Soesilo, Y. (2013). Pola Pendidikan Seks Alkitabiah bagi Remaja dalam Keluarga Menurut Kitab Amsal. Antusias: Jurnal Teologi dan Pelayanan, 2(2), 84-104
Stanton, L \& Jones, B. (2004) Bagaimana dan Kapan Memberitahu Anak Anda Mengenai Seks, Surabaya: Momentum.

Subagyo, A. B. (2004), Pengantar Riset Kuantitatif dan Kualitatif Termasuk Riset Teologi dan Keagamaan. Bandung: Kalam Hidup

Suleeman, S. (2013). Sejarah Seksualitas dalam Kekristenan. Retrieved from http://suarakita.org/wp-content/

Susabda, Y. (2015). Pastoral Konseling. Malang: Gandum Mas

Thianto, Y. (2001). Reformasi, Teologi dan Kehidupan Sehari-hari: Ajaran John Calvin dan Konsistori di Geneva tentang Pernikahan. Veritas: Jurnal Teologi dan Pelayanan, 2(2), 185-208

Toton, S. C. (2006). Justice Education: From Service to Solidarity. Milwaukee: Marquette University Press

Tu'u, T. (1988). Etika dan Pendidikan Seksual. Bandung: Kalam Hidup. 